\title{
Incidence of Late Thromboembolic Events After Catheter Ablation of Atrial Fibrillation
}

\author{
Atsuhiko Yagishita, MD; Yoshihide Takahashi, MD; Atsushi Takahashi, MD; Akira Fujii, MD; \\ Shigeki Kusa, MD; Tadashi Fujino, MD, PhD; Toshihiro Nozato, MD, PhD; \\ Taishi Kuwahara, MD; Kenzo Hirao, MD, PhD; Mitsuaki Isobe, MD, PhD
}

\begin{abstract}
Background: A low incidence of thromboembolic events after successful catheter ablation of atrial fibrillation (AF) during a mid-term follow-up period was recently reported. However, because the incidence of such events over the long term is unknown, we investigated the late incidence of thromboembolic events after catheter ablation.
\end{abstract}

Methods and Results: Patients with paroxysmal and persistent AF undergoing catheter ablation and being followed up for at least 24 months formed the study group $(n=524) ; 82$ patients (16\%) had CHADS 2 scores of at least 2 . Mean follow-up was $44 \pm 13$ months. Warfarin was discontinued in 400 (93\%) of 429 patients (82\% of 524 patients) without AF recurrence. None of the patients without AF recurrence suffered thromboembolic events, whereas 3 of 95 patients $(3 \%)$ with AF recurrence did $(P<0.001)$. One of the 3 was a late $A F$ recurrence occurring $>12$ months after catheter ablation. There were 2 nonfatal major hemorrhagic events in patients with AF recurrence who continued on warfarin, but no hemorrhagic events were observed in patients free from $A F(P=0.002)$.

Conclusions: Maintenance of sinus rhythm after catheter ablation of AF was associated with a lower incidence of thromboembolic events during long-term follow-up $>3$ years. This result suggests that catheter ablation reduces thromboembolic events if patients continue anticoagulation regardless of the ablation outcome. (Circ J 2011; 75: 2343-2349)

Key Words: Atrial fibrillation; Catheter ablation; Thromboembolic events

$\mathbf{T}$ hromboembolic events are a serious complication of atrial fibrillation (AF) and their prevention is a major goal for the management of patient with $\mathrm{AF} .{ }^{1} \mathrm{The}$ AFFIRM study demonstrated the necessity of continued anticoagulation therapy even in AF patients in whom sinus rhythm was maintained by antiarrhythmic drugs. ${ }^{2}$ Catheter ablation has emerged in recent years as a therapeutic option for rhythm control of drug-refractory AF. It is conceivable that rhythm control of $\mathrm{AF}$ achieved by catheter ablation might have an outcome different from that achieved by antiarrhythmic drugs with respect to the risk for stroke. Indeed, a recent multicenter cohort study that followed patients for a maximum of 28 months suggested that successful AF ablation abbreviated the necessity of anticoagulation. ${ }^{3}$ Considering the progressive nature of $\mathrm{AF}$, longer-term follow-up data may provide additional information. In the present study, patients who had undergone AF ablation were followed for a minimum of 2 years, and we report the rate of thromboembolic and hemorrhagic events during the followup period.

\section{Editorial p 2312}

\section{Methods}

\section{Study Subjects}

The patients considered for inclusion in the present study were 659 patients with drug-refractory paroxysmal or persistent symptomatic $\mathrm{AF}$ who underwent catheter ablation at Yokosuka Kyousai Hospital from January 2003 to October 2006. The present study group comprised of $524(80 \%)$ of those patients whom we were able to follow for a minimum of 24 months. The patient characteristics were as follows: AF type: paroxysmal $362(69 \%)$, persistent 162; structural heart disease present in $86(16 \%)$; $\mathrm{CHADS}_{2}$ score $>2$ in 82 (16\%), of whom 34 (6\% of 524) had a history of thromboembolic events; mean age $60 \pm 10$ years (range 20-80); sex: males $427(81 \%)$, females 97 ; mean left atrial (LA) diameter $40 \pm 6 \mathrm{~mm}$; mean left ventricular ejection fraction $0.64 \pm 0.10$.

Received January 24, 2011; revised manuscript received May 15, 2011; accepted May 26, 2011; released online July 21, 2011 Time for primary review: 8 days

Department of Cardiovascular Medicine, Tokyo Medical and Dental University, Tokyo (A.Y., K.H., M.I.); Cardiovascular Center, Yokosuka Kyosai Hospital, Yokosuka (Y.T., A.T., A.F., S.K., T.F., T.N., T.K.), Japan

Mailing address: Atsuhiko Yagishita, MD, Department of Cardiovascular Medicine, Tokyo Medical and Dental University, 1-5-45 Yushima, Bunkyo-ku, Tokyo 113-8510, Japan. E-mail: atsuhikoyagishita@nifty.com

ISSN-1346-9843 doi:10.1253/circj.CJ-11-0065

All rights are reserved to the Japanese Circulation Society. For permissions, please e-mail: cj@j-circ.or.jp 


\begin{tabular}{|c|c|c|c|}
\hline & $\begin{array}{c}\text { Patients free } \\
\text { from AF }(n=429)\end{array}$ & $\begin{array}{l}\text { Patients with AF } \\
\text { recurrence }(n=95)\end{array}$ & $P$ value \\
\hline Male, $n(\%)$ & $352(82.1)$ & $75(79.0)$ & 0.469 \\
\hline Age (years) & $60.0 \pm 10.0$ & $59.3 \pm 10.8$ & 0.378 \\
\hline Hypertension, $\mathbf{n}(\%)$ & $170(39.7)$ & $39(41.1)$ & 0.818 \\
\hline Diabetes mellitus, $\mathbf{n}(\%)$ & $38(8.9)$ & $9(9.5)$ & 0.844 \\
\hline HF, n (\%) & $31(7.3)$ & $11(11.6)$ & 0.208 \\
\hline \multicolumn{4}{|l|}{ Structural heart disease, $\mathrm{n}(\%)$} \\
\hline Hypertrophic cardiomyopathy, n (\%) & $7(1.6)$ & $2(2.1)$ & 0.670 \\
\hline DCM, n (\%) & $14(3.3)$ & $5(5.3)$ & 0.363 \\
\hline Valvular heart disease, $\mathrm{n}(\%)$ & $20(4.7)$ & $6(6.3)$ & 0.445 \\
\hline Coronary heart disease, $\mathrm{n}(\%)$ & $21(4.9)$ & $11(11.6)$ & 0.029 \\
\hline Prior history of cerebral vascular disease, $\mathrm{n}(\%)$ & $28(6.5)$ & $6(6.3)$ & 1.000 \\
\hline $\mathrm{CHADS}_{2}$ score $\geq 2, \mathrm{n}(\%)$ & $65(15.2)$ & $17(17.9)$ & 0.755 \\
\hline Persistent AF, n (\%) & $122(28.4)$ & $40(42.1)$ & 0.014 \\
\hline \multicolumn{4}{|l|}{ Echocardiography } \\
\hline Ejection fraction (\%) & $64.5 \pm 9.8$ & $64.5 \pm 8.5$ & 0.978 \\
\hline LA size $(\mathrm{mm})$ & $39.5 \pm 6.0$ & $40.0 \pm 7.1$ & 0.503 \\
\hline LA appendage flow velocity $(\mathrm{cm} / \mathrm{s})$ & $55.5 \pm 25.6$ & $52.2 \pm 24.0$ & 0.280 \\
\hline
\end{tabular}

$A F$, atrial fibrillation; HF, heart failure; DCM, dilated cardiomyopathy; LA, left atrium.

\section{Patients without AF recurrence $(\mathrm{n}=\mathbf{4 2 9})$}

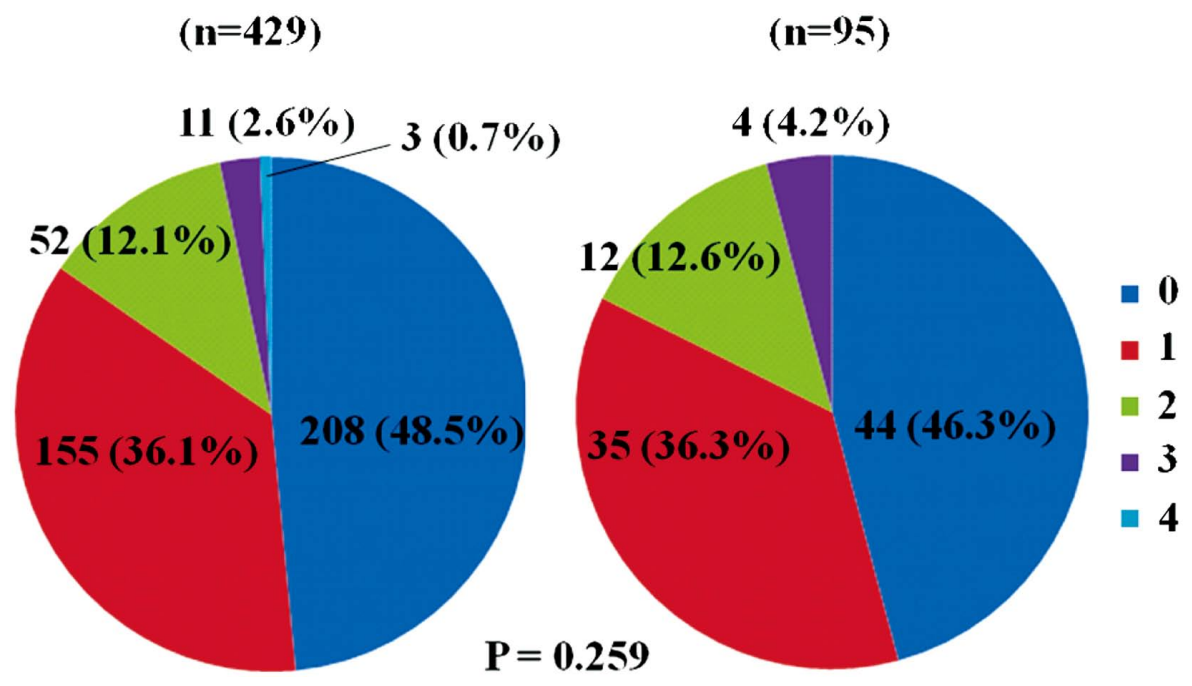

Patients with AF recurrence $(\mathbf{n}=95)$

Figure 1. Proportion of patients in each $\mathrm{CHADS}_{2}$ score was similar between patients with and without recurrence of atrial fibrillation.

\section{Radiofrequency Catheter Ablation}

Radiofrequency catheter ablation was performed after discontinuation of antiarrrhythmic drugs for $\geq 5$ half-lives. Transesophageal echocardiography was performed in all patients within the $24 \mathrm{~h}$ before the procedure. Details of the ablation technique have been described previously.,5 In brief, radiofrequency energy was delivered using an 8-mm tip electrode ablation catheter. Pulmonary vein isolation and cavotricuspid isthmus ablation were performed in all patients. In patients with persistent $\mathrm{AF}$, electrogram-based ablation in the LA or coronary sinus, linear ablation at the LA roof and/or mitral isthmus, and superior vena cava isolation were additionally performed at the discretion of the operator. ${ }^{6}$

\section{Anticoagulation Protocol}

All patients were treated with warfarin for at least 1 month before catheter ablation. Warfarin was discontinued 3 days before the procedure, after which heparin was administered intravenously until the procedure. During the procedure, 2 boluses of intravenous heparin $(50 \mathrm{IU} / \mathrm{kg})$ were administered, 1 prior to the transseptal puncture, and then another immediately following the transseptal puncture. The activated clotting time was evaluated every $30 \mathrm{~min}$ and maintained at $\geq 300$ s during the procedure with a continuous infusion of heparin $(1,000 \mathrm{IU} / \mathrm{h})$. At the 
Table 2. Medication After Catheter Ablation

\begin{tabular}{lccr} 
Patients free & $\begin{array}{c}\text { Patients with AF } \\
\text { from AF }(\mathbf{n}=\mathbf{4 2 9})\end{array}$ & P value \\
Warfarin, $\mathrm{n}(\%)$ & $29(6.8 \%)$ & $62(65.3 \%)$ & $<0.001$ \\
Aspirin, $\mathrm{n}(\%)$ & $65(15.2 \%)$ & $20(21.1 \%)$ & 0.167 \\
ACEl/ARB, $\mathrm{n}(\%)$ & $108(25.2 \%)$ & $29(30.5 \%)$ & 0.303 \\
$\beta$-blocker, $\mathrm{n}(\%)$ & $69(16.1 \%)$ & $25(26.3 \%)$ & 0.026 \\
Antiarrhythmic drug, $\mathrm{n}(\%)$ & $29(6.7 \%)$ & $50(52.6 \%)$ & $<0.001$ \\
Statin, $\mathrm{n}(\%)$ & $56(13.1 \%)$ & $11(11.6 \%)$ & 0.865 \\
\hline
\end{tabular}

ACEl, angiotensin-converting enzyme inhibitor; ARB, angiotensin receptor blocker. Other abbreviation see in Table 1.

a

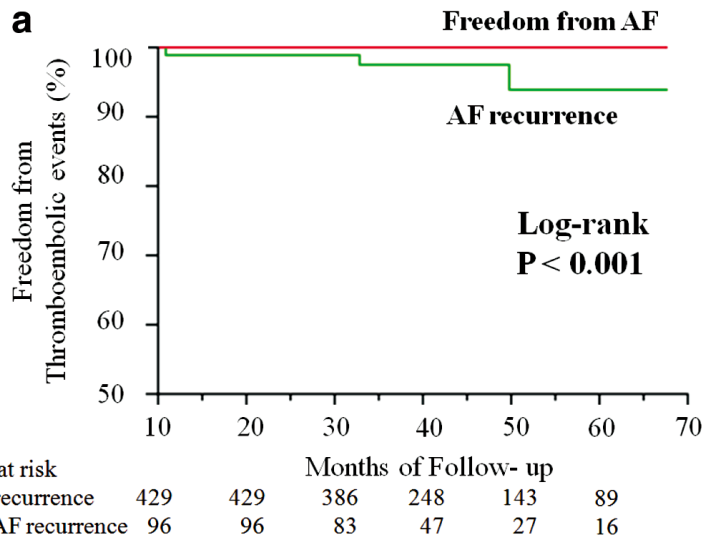

b

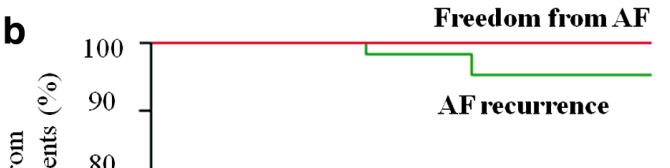

园

No. at risk

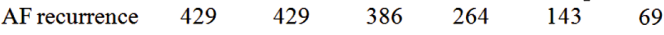

No AF recurrence $96 \quad 95 \quad 76 \quad 46 \quad r 7 \quad 27 \quad 18$

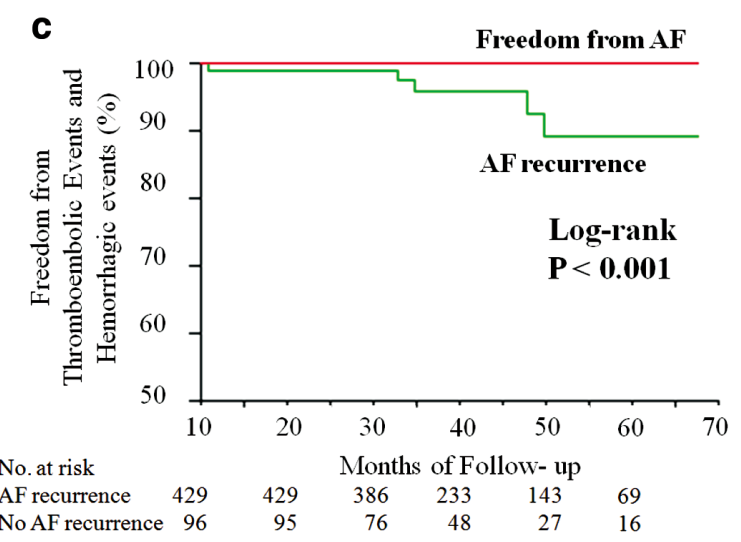

d

Freedom from AF

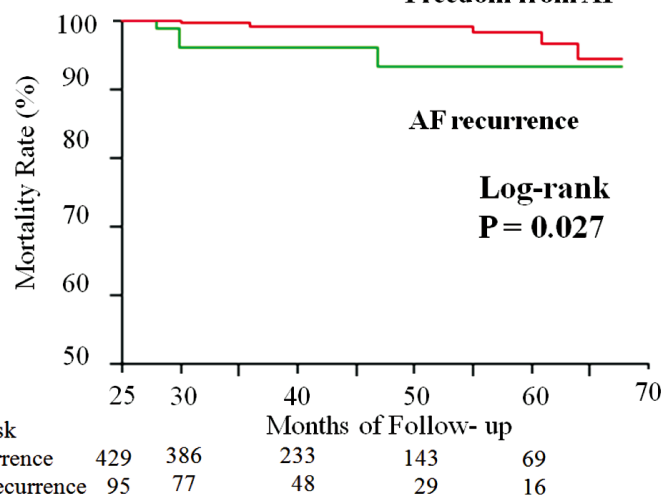

Figure 2. (a) Kaplan-Meier estimates of the freedom from thomboembolic events. Freedom from atrial fibrillation (AF; Red line) vs. AF recurrence (Green line). Thromboembolic events were significantly lower in patients free from AF. (b) Kaplan-Meier estimates of the freedom from hemorrhagic events. Freedom from AF (Red line) vs. AF recurrence (Green line). Hemorrhagic events were significantly lower in patients free from AF. (c) Kaplan-Meier estimates of the freedom from thromboembolic and hemorrhagic events. Freedom from AF (Red line) vs. AF recurrence (Green line). Thromboembolic and hemorrhagic events were significantly lower in patients free from AF. (d) Kaplan-Meier estimates of the mortality rate. Freedom from AF (Red line) vs. AF recurrence (Green line). The mortality rate was lower in patients free from AF.

end of the procedure, heparin was discontinued and protamine was administered prior to femoral venous sheath removal. Warfarin was re-initiated on the day of the procedure and continued for at least 3 months to keep the international normalized ratio (INR) between 2 and 3. Continuation of warfarin beyond 3 months was determined at the discretion of the physician.

\section{Post-Ablation Follow-up}

Patients were followed up in an outpatient clinic at 1, 3 and
6 months after the procedure, then followed up either in an outpatient clinic or contacted by telephone every 12 months. AF recurrence was assessed by patient symptoms in conjunction with serial electrocardiograms performed during every outpatient clinic visit and 24-h Holter monitor recordings performed at 3, 6 and 12 months. Discovery of persistent or paroxysmal episode of AF/AT continuous for $\geq 30$ s after the 2-month blanking period was regarded as a recurrence of tachyarrhythmia, and a repeat procedure was performed. Freedom from AF 


\begin{tabular}{|ccccccc|}
\hline \multicolumn{2}{|c|}{ Table 3. Patients With Thromboembolic Events } & & & & \\
Patient no. & Age/sex & Type of AF & $\begin{array}{c}\text { Underlying } \\
\text { disease }\end{array}$ & $\begin{array}{c}\text { CHADS } \\
\text { score }\end{array}$ & $\begin{array}{c}\text { Time to event } \\
\text { after ablation } \\
\text { (months) }\end{array}$ & INR \\
1 & $74 / F$ & Paroxysmal & HF & 3 & 24 & 1.02 \\
2 & $62 / F$ & Paroxysmal & Prior stroke & 2 & 26 & 1.38 \\
3 & $59 / \mathrm{M}$ & Paroxysmal & $\begin{array}{c}\text { Hypertension, } \\
\text { chronic kidney } \\
\text { disease }\end{array}$ & 1 & 50 & $\begin{array}{c}\text { Not available } \\
\text { (warfarin was } \\
\text { discontinued) }\end{array}$ \\
\hline
\end{tabular}

INR, international normalized ratio. Other abbreviations see in Table 1.

\begin{tabular}{|c|c|c|c|}
\hline & $\begin{array}{l}\text { Patients with } \\
\text { thromboembolic } \\
\text { events }(n=3)\end{array}$ & $\begin{array}{l}\text { Patients without } \\
\text { thromboembolic } \\
\text { events }(n=521)\end{array}$ & $P$ value \\
\hline Male, n (\%) & $1(33.3)$ & $426(81.7)$ & 0.090 \\
\hline Age (years) & $59.8 \pm 10.1$ & $65.0 \pm 7.9$ & 0.378 \\
\hline Hypertension, n (\%) & $1(33.3)$ & $208(40.0)$ & 1.000 \\
\hline Diabetes mellitus, $\mathrm{n}(\%)$ & $1(33.3)$ & $46(8.9)$ & 0.247 \\
\hline HF, n (\%) & $1(33.3)$ & $41(7.9)$ & 0.223 \\
\hline \multicolumn{4}{|l|}{ Structural heart disease, $\mathrm{n}(\%)$} \\
\hline Hypertrophic cardiomyopathy, n (\%) & $0(0)$ & $9(1.7)$ & 1.000 \\
\hline DCM, n (\%) & $0(0)$ & $19(3.7)$ & 1.000 \\
\hline Valvular heart disease, $\mathrm{n}(\%)$ & $2(66.7)$ & $24(4.6)$ & 0.007 \\
\hline Coronary heart disease, $\mathrm{n}(\%)$ & $1(33.3)$ & $31(6.0)$ & 0.729 \\
\hline Prior history of cerebral vascular disease, $\mathrm{n}(\%)$ & $1(33.3)$ & $33(6.3)$ & 0.183 \\
\hline $\mathrm{CHADS}_{2}$ score $\geq 2, \mathrm{n}(\%)$ & $2(66.7)$ & $80(15.4)$ & 0.065 \\
\hline Persistent AF, n (\%) & $0(0)$ & $162(31.1)$ & 0.556 \\
\hline AF recurrence & $3(100)$ & $92(17.6)$ & 0.006 \\
\hline Warfarin, n (\%) & $2(67)$ & $89(17.1)$ & 0.080 \\
\hline \multicolumn{4}{|l|}{ Echocardiography } \\
\hline Ejection fraction (\%) & $71.7 \pm 1.8$ & $64.4 \pm 96$ & 0.286 \\
\hline LA size $(\mathrm{mm})$ & $36.2 \pm 3.1$ & $39.6 \pm 6.2$ & 0.441 \\
\hline LA appendage flow velocity $(\mathrm{cm} / \mathrm{s})$ & $88.3 \pm 15.2$ & $54.7 \pm 25.3$ & 0.061 \\
\hline
\end{tabular}

Abbreviations see in Table 1.

was defined as no detectable AF episode by using these modalities after the final procedure. AF recurrence $>12$ months after catheter ablation was defined as late AF recurrence. Thromboembolic events, especially cerebrovascular events including transient ischemic events and ischemic stroke, were defined as the abrupt onset of focal neurological deficit. ${ }^{7}$ Thromboembolic events occurring $\geq 1$ month after the procedure were defined as late thromboembolic events. The endpoints of the study were late thromboembolic events, hemorrhagic events and mortality.

\section{Statistical Analysis}

Continuous variables are expressed as mean \pm 1 standard deviation. Comparison between groups was performed with Student's t-test or the Wilcoxon rank-sum test, as appropriate. For categorical data, Fisher's exact test was applied. A P value $<0.05$ (2-tailed) was considered to indicate statistical significance. Kaplan-Meier analysis was performed to assess differences in the incidence of late thromboembolic events, hemorrhagic events and mortality rate between patients with and without AF recurrence. All statistical analyses were performed using commercially available computer software (JMP version 6, SAS Institute, Tokyo, Japan).

\section{Results}

Among the 524 patients, 429 (82\%) maintained sinus rhythm after catheter ablation. Mean follow-up duration was $44 \pm 13$ months. The proportion of patients with persistent AF (42.1\%) was significantly higher in patients with AF recurrence compared with those without $(28.4 \%, \mathrm{P}=0.014$, Table 1$)$. Persistent $\mathrm{AF}$ was the sole independent predictor for $\mathrm{AF}$ recurrence in multivariable analysis (odds ratio 2.00 ; $95 \%$ confidence interval 1.23-3.11; $\mathrm{P}=0.004)$. $\mathrm{CHADS}_{2}$ score was similar between patients with and without AF recurrence (Figure 1). Among the 95 patients with $\mathrm{AF}$ recurrence, late $\mathrm{AF}$ recurrence was observed in 3 patients. Time from the catheter ablation to these late $\mathrm{AF}$ recurrences was 25,31 and 40 months, respectively.

\section{Anticoagulation Status}

Warfarin was discontinued in 432 (82\%) of 524 patients after the procedure. Of the 429 patients who remained free from AF throughout the follow-up period, only $29(7 \%)$ were continued on warfarin, whereas 63 of the 95 patients $(66 \%)$ in whom $\mathrm{AF}$ recurred were continued on warfarin (Table 2). The reason for warfarin discontinuation in the 32 patients with $\mathrm{AF}$ recurrence was a $\mathrm{CHADS}_{2}$ score of 0 in 26 patients, and drug intolerance in the remaining 6 patients even though their $\mathrm{CHADS}_{2}$ score 


\begin{tabular}{|c|c|c|c|c|c|c|}
\hline Patient no. & Age/sex & Underlying disease & $\begin{array}{c}\text { Final } \\
\text { rhythm }\end{array}$ & $\begin{array}{c}\text { Anticoagulation } \\
\text { therapy }\end{array}$ & Cause of death & $\begin{array}{l}\text { Follow-up } \\
\text { (months) }\end{array}$ \\
\hline 1 & $74 / F$ & Valvular heart disease & $\mathrm{AF}$ & Warfarin & $\mathrm{HF}$ & 24 \\
\hline 2 & $60 / F$ & CAD & $\mathrm{AF}$ & None & Interstitial pneumonia & 28 \\
\hline 3 & $55 / M$ & DCM & SR & Warfarin & Sudden death & 30 \\
\hline 4 & $67 / F$ & DCM & AF & Warfarin & Interstitial pneumonia & 30 \\
\hline 5 & $76 / \mathrm{M}$ & Hypertension, CAD & SR & None & Gastric cancer & 36 \\
\hline 6 & $64 / M$ & None & AF & None & Lung cancer & 47 \\
\hline 7 & $64 / M$ & Valvular heart disease & SR & None & Sepsis & 55 \\
\hline 8 & $71 / \mathrm{M}$ & $\begin{array}{l}\text { Hypertrophic } \\
\text { cardiomyopathy }\end{array}$ & SR & None & Sepsis & 61 \\
\hline 9 & $53 / M$ & Hypertension & SR & None & Pancreatic cancer & 64 \\
\hline 10 & $69 / M$ & None & $\mathrm{AF}$ & Warfarin & Pneumonia & 67 \\
\hline
\end{tabular}

CAD, coronary artery disease; SR, sinus rhythm. Other abbreviations see in Table 1.

was $\geq 2$. There were 82 patients with $\mathrm{CHADS}_{2}$ score $\geq 2,65$ (79\% of 82 ) of whom were without AF recurrence. Warfarin was discontinued in 53 patients $(82 \%)$ of the latter group.

\section{Late Thromboembolic Events}

None of the 429 patients without AF recurrence had thromboembolic events, whereas 3 of 95 patients with AF recurrence had thromboembolic events. Kaplan-Meier estimate of freedom from thromboembolic events at 5 years was $100 \%$ in patients free from $\mathrm{AF}$, whereas the rate was $94 \%$ in patients with $\mathrm{AF}$ recurrence (log-rank test: $\mathrm{P}<0.001$, Figure $2 \mathrm{a}$ ). The clinical characteristics of the 3 patients who had thromboembolic events are shown in Table 3. The first was a 74-year-old woman with a $\mathrm{CHADS}_{2}$ score of 3 (hypertension, diabetes and heart failure) who had a cerebral infarction of the right hemisphere 24 months after catheter ablation. At the time of the infarction, she had been on warfarin since confirmation of AF recurrence at the 3-month follow-up visit. However, the INR was 1.02. The second case was a 62-year-old woman with a $\mathrm{CHADS}_{2}$ score of 2 (history of prior stroke) who suffered cerebral infarction of the left hemisphere 26 months after catheter ablation. She also was on warfarin, which had been resumed when AF recurrence was confirmed by Holter monitor recording 10 months after catheter ablation. The INR was 1.38 at the time of infarction. The third was a 59-year-old man with a $\mathrm{CHADS}_{2}$ score of 1 (hypertension) and history of endstage renal disease because of chronic glomerular nephritis. He had a transient ischemic attack 50 months after the catheter ablation. Although late AF recurrence was confirmed by patient symptoms and electrocardiogram 40 months after the ablation, warfarin was not reinitiated. Table 4 summarizes the comparisons of baseline patient characteristics in patients with and without thromboembolic events. The prevalence of valvular heart disease and the incidence of AF recurrence were significantly higher in patients with thromboembolic events compared with those without thromboembolic events. However, neither was an independent predictor of late thromboembolic events in the multivariable analysis.

\section{Hemorrhagic Events}

Non-fatal hemorrhagic events occurred in 2 of 95 patients with AF recurrence, both of whom were on warfarin, whereas no hemorrhagic events occurred in patients free from AF. The 2 events were intramuscular bleeding of a left lower extremity 47 months after catheter ablation and gastrointestinal bleeding 35 months after catheter ablation. The INR at the time was 1.83 and 2.83, respectively. The HAS-BLED bleeding risk score was similar between patients with and without hemorrhagic events $(0.50 \pm 0.71$ vs. $0.78 \pm 0.79)$. Kaplan-Meier estimates of freedom from hemorrhagic events at 5 years were $100 \%$ in patients free from $\mathrm{AF}$, and $95 \%$ in patients with $\mathrm{AF}$ recurrence (log-rank test: $\mathrm{P}=0.002$, Figure $2 \mathrm{~b}$ ). The eventfree survival estimates for freedom from thromboembolic and hemorrhagic events were significantly different between the 2 groups (Figure $2 \mathrm{c}$ ).

\section{Mortality Rate}

There were 10 deaths (Table 5), 5 among the 429 patients maintaining sinus rhythm (1 sudden death, 4 non-cardiac deaths), and 5 among the 95 patients with AF recurrence (1 $\mathrm{CHF}, 4$ non-cardiac deaths). Kaplan-Meier estimates of freedom from death at 5 years were $95 \%$ in patients free from $\mathrm{AF}$, and $94 \%$ in patients with $\mathrm{AF}$ recurrence (log-rank test: $\mathrm{P}=0.027$, Figure 2d). Although the all-cause mortality rate was significantly different between the 2 groups, the cardiac death rate was not different between them $(0.2 \%$ vs. $0.9 \%$; $\mathrm{P}=0.21)$.

\section{Discussion}

The main findings of the present study are: (1) freedom from AF was associated with low incidence of thromboembolic events during long-term follow-up $>3$ years after catheter ablation despite discontinuation of anticoagulants in $90 \%$ of the patients; (2) hemorrhagic events occurred only in patients who continued on warfarin; and (3) late AF recurrence with subsequent thromboembolic events was observed.

\section{Thromboembolic Events During Long-Term Follow up After Catheter Ablation}

There have been several studies showing that maintenance of sinus rhythm is associated with low incidence of thromboembolic events after catheter ablation. ${ }^{3,8,9}$ Among them, the longest mean follow-up period was 28 months and thromboembolic events were lower in patients free from atrial tachyarrhythmia, compared with those without, after catheter ablation of $\mathrm{AF}$ $(0.07 \%$ vs. $0.45 \%) .{ }^{3}$ The present study extended the mean follow-up period to greater than 3 years and demonstrated a similar trend (ie, elimination of atrial arrhythmias by catheter ablation was found to attenuate risk of thromboembolism in patients with AF). In our univariable analysis, both the incidence of AF recurrence and the prevalence of valvular heart disease were high in patients with thromboembolic events compared with patients without. However, they were not independent predic- 
tors in the multivariable analysis, perhaps because of the small number of thromboembolic events in the present study.

\section{Antithromboembolic Therapy After Catheter Ablation}

In this study, warfarin was discontinued in $>90 \%$ of patients without AF recurrence. In particular, approximately $80 \%$ of the 82 patients with $\mathrm{CHADS}_{2}$ score $\geq 2$ did not have AF recurrence and none suffered thromboembolic consequences despite termination of warfarin. According to the HRS/EHRA/ECAS Expert Consensus Statement, ${ }^{10}$ discontinuation of warfarin therapy post ablation is not generally recommended in patients who have a $\mathrm{CHADS}_{2}$ score $\geq 2$ because of limited data regarding the safety of treatment cessation. There is another report advocating the need for continued warfarin after catheter ablation in patients with thromboembolic risk. ${ }^{11}$ Because we had enrolled patients with $\mathrm{CHADS}_{2}$ score $\geq 2$ who underwent catheter ablation before the publication of those reports, warfarin was discontinued in patients with thromboembolic risk in the same manner as in patients without thromboembolic risk. Considering that all thromboembolic events observed in our study occurred in patients with thromboembolic risk, warfarin should be continued in high-risk patients, regardless of their rhythm status after catheter ablation. However, in their report Themistoclakis et al emphasized the benefit of discontinuing warfarin even in high-risk patients for thromboembolic events if the patient was free from AF, because of the increased risk of a major hemorrhage compared with the low thromboembolic event rate (2\% vs. $0.04 \%){ }^{3}$ In the present study, there were 2 hemorrhagic events that occurred in patients who had AF recurrence and continued to be on warfarin, whereas no thromboembolic or hemorrhagic events occurred in AF-free patients who discontinued warfarin. Obviously, a prospective study with a large number of high-risk patients will be necessary to investigate the incidence of stroke and bleeding after catheter ablation. If warfarin is discontinued after successful ablation, it should be reinstated once AF recurrence is confirmed in high-risk patients for thromboembolic events, regardless of the type of AF. A previous study demonstrated the presence of hypercoagulability in the LA of patients with paroxysmal AF and thromboembolic risk, even in the non-paroxysmal period, suggesting that patients with paroxysmal AF are at high risk for developing cerebral thromboembolism even during sinus rhythm. ${ }^{12}$ Another study demonstrated that stroke rates in patients with paroxysmal AF were similar to those in patients with persistent $\mathrm{AF}$ and similar stroke risk factors, ${ }^{13}$ and that advanced age and structural heart disease were independent predictors for thrombus formation in the LA. ${ }^{14}$ Therefore, resumption of warfarin should not be based on the type of AF, but on the thromboembolic risk in patients with AF recurrence. In addition to the reinstating of warfarin in patients with $\mathrm{AF}$ recurrence, maintenance of the therapeutic range of warfarin is critical. In the present study, the INR were below the therapeutic range in the 2 patients with thromboembolic events who had continued on warfarin, which suggests the importance of both close monitoring of INR and determining the appropriate warfarin dose.

\section{Undetected AF Recurrence}

Although warfarin was discontinued in most of the patients free from AF without causing any thromboembolic events in this study, the possibility of undetected AF recurrence was a major motivation to continue warfarin in a minority of patients. There is a report that asymptomatic episodes significantly increase after catheter ablation in patients presenting with highly symptomatic AF before catheter ablation. ${ }^{15}$ According to 2 reports in which AF recurrence was assessed by permanent pacemaker (PPM), continuous monitoring provided by the PPM was able to detect significantly more AF episodes than routine follow-up methods. One report determined that PPM detected atrial tachyarrhythmia recurrences in $30 \%$ of patients without symptoms of $\mathrm{AF}$, and revealed that most of these episodes were $<60 \mathrm{~s}$ in duration and subsided within 3 months. ${ }^{16}$ The second report compared freedom from AF as assessed by patient symptoms (71\% of patients after catheter ablation), 24- to 48-h Holter monitor recording every 6 months (64\%), 1-week Holter monitor recording every 6 months (58\%), and continuous monitoring by the PPM (43\%). The authors concluded that the more rigorous the monitoring, the more AF was uncovered. However, the duration of atrial tachyarrhythmia was significantly reduced from a median of 3.6 to $0.3 \mathrm{~h}$ /day after catheter ablation. ${ }^{17}$ Data about the association between the duration of AF episodes and the occurrence of thromboembolic events are scarce Capucci et al that found that thromboembolic events were frequently observed only in patients in whom the duration of device-detected AF was longer than $24 \mathrm{~h} .{ }^{18}$ Nademanee et al found that the incidence of thromboembolic events associated with undetected $\mathrm{AF}$ was low and concluded that undetected AF might be of short duration and inconsequential. ${ }^{9}$ In summary, the literature suggests that although the number of undetected AF episode may increase after catheter ablation, the duration of individual episodes decreases, usually to less than $24 \mathrm{~h}$, a duration not associated with thromboembolic events. In the present study, undetected AF recurrence must have been present, because it was not assessed by continuous cardiac rhythm monitoring devices. However, because no thromboembolic events were associated with undetected AF recurrence, the follow-up method of using patient symptoms, serial electrograms and 24-h Holter monitor recordings to catch only significant AF recurrences associated with thromboembolic events may be sufficient. Combined with the fact that the prolonged use of event monitoring and PPM in all patients after catheter ablation would not be feasible in clinical practice, the results of the present study demonstrate the applicability and frequency of our follow-up method after catheter ablation.

\section{Late AF Recurrence}

According to the literature, the incidence of late $\mathrm{AF}$ recurrence is $5.8-13.0 \%$ at 2 years, and $25.5-46.8 \%$ at 5 years ${ }^{19-22}$ or approximately $7 \%$ per year after the first year. ${ }^{23}$ The incidence of late AF recurrence was lower in the present study than in those previous reports. In addition to institutional differences, this is likely because late $\mathrm{AF}$ recurrence was defined as $\mathrm{AF}$ recurrence after the initial procedure in the previous studies, whereas we defined it as recurrence of AF after the last of one or more ablations. In line with previous reports, which demonstrated that late AF recurrence is more likely to occur in patients with hypertension, ${ }^{21}$ persistent $\mathrm{AF}$, and in older patients, ${ }^{23}$ a late AF recurrence followed by a thromboembolic event occurred in an aged hypertensive patient in our study. In addition to the fact that persistent $\mathrm{AF}$ was the sole independent predictor for $\mathrm{AF}$ recurrence in the present study, clinicians should be aware of the importance of long-term vigilance for $\mathrm{AF}$ recurrence, especially in patients with thromboembolic risk and/or persistent AF.

\section{Study Limitations}

First, our study was small, retrospective and an observational cohort study. Second, most of the patients enrolled in our study were at low to moderate risk for thromboembolic events, which may have led to the low incidence of thromboembolic 
events. To address these 2 issues, a larger and randomized trial including a greater proportion of patients with high thromboembolic risk would be required for a comparison of the continuation or discontinuation of warfarin. However, discontinuation of anticoagulation in patients with a high risk of thromboembolism after ablation may be ethically unfeasible. Thus, it is still safe and ethical to continue warfarin in patients with thromboembolic risk regardless of the cardiac rhythm after catheter ablation. Third, it is likely that some of the patients we regarded as being free from AF had undetected AF recurrences in the absence of continuous monitoring devices. These false negatives, if detected, should have been included in the patients with AF recurrence. Because no late thromboembolic events were observed in patients free of AF (true and false negatives), we believe our results and methods for AF recurrence detection are nevertheless relevant in clinical practice. Fourth, we partially attributed the lower incidence of late $\mathrm{AF}$ recurrence in our study to the difference in the definition of late AF recurrence, but the decreasing frequency with which we monitored patients after 12 months after the final procedure may have also been a factor. Therefore, in future studies close follow-up during a long-term period should be continued in order not to overlook significant AF episodes. Lastly, screening of stroke using magnetic resonance imaging was not performed, so minor stroke events may have been undetected.

\section{Conclusion}

Maintenance of sinus rhythm after catheter ablation of AF was associated with a lower incidence of thromboembolic events during a long-term follow-up. Stroke occurred in 1 patient who had AF recurrence late ( $\geq 1$ year) after catheter ablation. AF may occur late after catheter ablation, which is not predictive by any cardiac rhythm monitoring. Thus, discontinuation of warfarin after successful ablation should be based on risk factors. However, anticoagulation therapy using warfarin includes some issues; such as bleeding, intolerability, or unstable INR control, and these may be attributable to thromboembolism in patients who are taking warfarin. The results of the present study suggest that catheter ablation reduces thromboembolic events if patients continue anticoagulation regardless of the ablation outcome.

\section{Disclosure}

There are no financial or other relations that lead to a conflict of interest.

\section{References}

1. European Heart Rhythm Association, Heart Rhythm Society, Fuster V, Rydén LE, Cannom DS, Crijns HJ, et al. ACC/AHA/ESC 2006 Guidelines for the Management of Patients with Atrial Fibrillation: A report of the American College of Cardiology/American Heart Association Task Force on Practice Guidelines and the European Society of Cardiology Committee for Practice Guidelines (Writing Committee to Revise the 2001 Guidelines for the Management of Patients With Atrial Fibrillation): Developed in collaboration with the European Heart Rhythm Association and the Heart Rhythm Society. Circulation 2006; 114: e257-e354.

2. Wyse DG, Waldo AL, DiMarco JP, Domanski MJ, Rosenberg Y, Schron EB, et al. A comparison of rate control and rhythm control in patients with atrial fibrillation. N Engl J Med 2002; 347: 1825-1833.

3. Themistoclakis S, Corrado A, Marchlinski FE, Jais P, Zado E, Rossillo $\mathrm{A}$, et al. The risk of thromboembolism and need for oral anticoagulation after successful atrial fibrillation ablation. J Am Coll Cardiol 2010; 55: 735-743.

4. Takahashi Y, Takahashi A, Miyazaki S, Kuwahara T, Takei A, Fujino $\mathrm{T}$, et al. Electrophysiological characteristics of localized reentrant atrial tachycardia occurring after catheter ablation of long-lasting persistent atrial fibrillation. J Cardiovasc Electrophysiol 2009; 20: 623-629.

5. Kuwahara T, Takahashi A, Kobori A, Miyazaki S, Takahashi Y, Takei A, et al. Safe and effective ablation of atrial fibrillation: Importance of esophageal temperature monitoring to avoid periesophageal nerve injury as a complication of pulmonary vein isolation. J Cardiovasc Electrophysiol 2009; 20: 1-6.

6. Haissaguerre M, Sanders P, Hocini M, Takahashi Y, Rotter M, Sacher $\mathrm{F}$, et al. Catheter ablation of long-lasting persistent atrial fibrillation: Critical structures for termination. J Cardiovasc Electrophysiol 2005; 16: $1125-1137$

7. Investigators SPiAF. Stroke Prevention in Atrial Fibrillation Study: Final results. Circulation 1991; 84: 527-539.

8. Oral H, Chugh A, Ozaydin M, Good E, Fortino J, Sankaran S, et al. Risk of thromboembolic events after percutaneous left atrial radiofrequency ablation of atrial fibrillation. Circulation 2006; 114: 759765 .

9. Nademanee K, Schwab MC, Kosar EM, Karwecki M, Moran MD, Visessook N, et al. Clinical outcomes of catheter substrate ablation for high-risk patients with atrial fibrillation. J Am Coll Cardiol 2008; 51: $843-849$.

10. European Heart Rhythm Association (EHRA), European Cardiac Arrhythmia Society (ECAS), American College of Cardiology (ACC), American Heart Association (AHA), Society of Thoracic Surgeons (STS), Calkins H, et al. HRS/EHRA/ECAS expert Consensus Statement on catheter and surgical ablation of atrial fibrillation: Recommendations for personnel, policy, procedures and follow-up. A report of the Heart Rhythm Society (HRS) Task Force on catheter and surgical ablation of atrial fibrillation. Heart Rhythm 2007; 4: 816-861.

11. Natale A, Raviele A, Arentz T, Calkins H, Chen SA, Haissaguerre M, et al. Venice Chart international consensus document on atrial fibrillation ablation. J Cardiovasc Electrophysiol 2007; 18: 560-580.

12. Motoki H, Tomita T, Aizawa K, Kasai H, Izawa A, Kumazaki S, et al. Coagulation activity is increased in the left atria of patients with paroxysmal atrial fibrillation during the non-paroxysmal period: Comparison with chronic atrial fibrillation. Circ J 2009; 73: 1403-1407.

13. Hart RG, Pearce LA, Rothbart RM, McAnulty JH, Asinger RW, Halperin JL. Stroke with intermittent atrial fibrillation: Incidence and predictors during aspirin therapy: Stroke Prevention in Atrial Fibrillation Investigators. J Am Coll Cardiol 2000; 35: 183-187.

14. Yamashita E, Takamatsu H, Tada H, Toide H, Okaniwa H, Takemura $\mathrm{N}$, et al. Transesophageal echocardiography for thrombus screening prior to left atrial catheter ablation. Circ J 2010; 74: 1081-1086.

15. Hindricks G, Piorkowski C, Tanner H, Kobza R, Gerds-Li JH, Carbucicchio C, et al. Perception of atrial fibrillation before and after radiofrequency catheter ablation: Relevance of asymptomatic arrhythmia recurrence. Circulation 2005; 112: 307-313.

16. Verma A, Minor S, Kilicaslan F, Patel D, Hao S, Beheiry S, et al. Incidence of atrial arrhythmias detected by permanent pacemakers (PPM) post-pulmonary vein antrum isolation (PVAI) for atrial fibrillation (AF): Correlation with symptomatic recurrence. J Cardiovasc Electrophysiol 2007; 18: 601-606.

17. Martinek M, Aichinger J, Nesser HJ, Ziegler PD, Purerfellner H. New insights into long-term follow-up of atrial fibrillation ablation: Full disclosure by an implantable pacemaker device. J Cardiovasc Electrophysiol 2007; 18: 818-823.

18. Capucci A, Santini M, Padeletti L, Gulizia M, Botto G, Boriani G, et al. Monitored atrial fibrillation duration predicts arterial embolic events in patients suffering from bradycardia and atrial fibrillation implanted with antitachycardia pacemakers. J Am Coll Cardiol 2005; 46: 1913 1920.

19. Sawhney N, Anousheh R, Chen WC, Narayan S, Feld GK. Five-year outcomes after segmental pulmonary vein isolation for paroxysmal atrial fibrillation. Am J Cardiol 2009; 104: 366-372.

20. Fichtner S, Czudnochowsky U, Hessling G, Reents T, Estner H, Wu J, et al. Very late relapse of atrial fibrillation after pulmonary vein isolation: Incidence and results of repeat ablation. Pacing Clin Electrophysiol 2010; 33: 1258-1263.

21. Shah AN, Mittal S, Sichrovsky TC, Cotiga D, Arshad A, Maleki K, et al. Long-term outcome following successful pulmonary vein isolation: Pattern and prediction of very late recurrence. J Cardiovasc Electrophysiol 2008; 19: 661-667.

22. Bertaglia E, Tondo C, De Simone A, Zoppo F, Mantica M, Turco P, et al. Does catheter ablation cure atrial fibrillation? Single-procedure outcome of drug-refractory atrial fibrillation ablation: A 6-year multicentre experience. Europace 2010; 12: 181-187.

23. Tzou WS, Marchlinski FE, Zado ES, Lin D, Dixit S, Callans DJ, et al. Long-term outcome after successful catheter ablation of atrial fibrillation. Circ Arrhythm Electrophysiol 2010; 3: 237-242. 